\title{
Advances in diagnosis and care of persons with DSD over the last decade
}

\author{
Peter A Lee ${ }^{1 *}$, Amy B Wisniewski ${ }^{2}$, Laurence Baskin ${ }^{3}$, Maria G Vogiatzi ${ }^{4}$, Eric Vilain ${ }^{5}$, Stephen M Rosenthal ${ }^{6}$, \\ Christopher Houk ${ }^{7}$ and on behalf of the Drugs and Therapeutics Committee of the Pediatric Endocrine Society
}

\begin{abstract}
It is clear that the major issues raised by the Chicago Disorders of Sex Development (DSD) Consensus meeting primarily the need of more data, especially outcome information, are still not available. Hence, there are insufficient data to merit another consensus statement. However, there has been a major shift in the thinking and approach to the care of patients with DSD. This was a consequence of the emphasis of the need to reconsider the criteria for sex assignment, to incorporate new genetic and hormonal knowledge in the care, and to investigate impact of surgical timing and techniques. Much of the reconsideration is in response to patient, family, social and legal demands, including the need for full disclosure and family or individual participation in decisions. Further, there remains a lack of sufficient information to provide predictors for future gender development. Hence, it still is impossible to develop specific clinical guidelines to apply to patients generally or individually. Thus, it is pertinent to periodically evaluate and assess some of these multifaceted changes. This report discusses cultural and social forces, legal factors, surgical perspectives, treatment shifts including psychological approaches, progress regarding genetic diagnosis, gender issue comparisons with transgender patients, and on-going research studies occurring since the consensus conference.
\end{abstract}

\section{Introduction}

The consensus report concerning DSD published in $2006[1,2]$ was an collective attempt to summarize and evaluate available information about optimizing treatment for DSD and identifying areas where further study was warranted. It has been nearly a decade since the Consensus Conference which: 1) redefined a broad variety of developmental conditions involving the reproductive system as Disorders of Sex Development (DSD), 2) created a new nomenclature based largely upon karyotype, 3) recognized the need to reconsider the criteria for those etiologies in which sex assignment was unclear, 4) reviewed pertinent physical findings and summarized genetic and hormonal criteria for diagnosis, 5) discussed surgical approaches and timing, 6) evaluated gonadal development from the perspective of fertility potential and risk of tumor development, and 7) identified the need for outcome studies including quality of life for

\footnotetext{
* Correspondence: plee@psu.edu

'Department of Pediatrics, Penn State Hershey Medical Center, The Milton S. Hershey Medical Center, 500 University Drive, PO Box 850, Hershey, PA 17033, USA

Full list of author information is available at the end of the article
}

those with DSD . Major concerns at that conference involved what genital and gonadal surgeries should be done and when these should be performed, and the lack of predictors for future gender development for DSD newborns without a clear diagnosis.

This report led to substantial changes in approaches to DSD patients as outlined in the paragraphs of this section below. This includes terminology, imaging techniques and diagnostic criteria, as well as the recognition of uncertainty about determinations of gender development pertinent in those situations when sex assignment is not apparent and is deemed to be necessary. While a shift in the psychological approach is not welldocumented, there is a sense than more transparency and shared decision making and certainly an awareness of the need for review of overall management.

While the term DSD has been widely adopted, there have been objections to the use of the word "Disorders" when used to describe less severe DSD cases leading to advocacy for a term to imply a variation of normal, such as "differences" or "variation". Further, it is unclear how this classification should be applied to conditions that 
do not present at birth with inconsistency between the karyotype, gonads and genital development, such as the less severe forms of congenital adrenal hyperplasia $(\mathrm{CAH})$. While there does not seem to be a consistent opinion in the CARES Foundation there is a push to remove $\mathrm{CAH}$ from the DSD nomenclature. The general classification of 46,XX, 46,XY and chromosomal DSD has also been adopted. While this classification is useful at the onset of the assessment toward an etiologic diagnosis, it, like the system it replaced may inappropriately emphasize the role of karyotype in gender development for some affected individuals. The consensus statement included recommendations for sex assignment for a relatively small group of DSD etiologies where outcomes were well-defined and predictable. While for most DSD patients sex assignment is apparent, for the minority for whom it is not, it remains problematic.

It was apparent at the Consensus Conference that environment (social rearing as a boy or girl) should not be considered a primary determinant of future gender development for most DSD patients. While it is now broadly recognized that androgen exposure to the central nervous system during mid-fetal life impacts gender development, this effect was not considered to be sufficient to guide sex assignment, particularly in those with 46,XY DSD and some testicular development. As a result, there has been a shift toward male sex assignment for patients in this category [3], with the caveat that assignment in those with dysgenic gonads and partial female and male internal reproductive system development (such as ovotesticular DSD), the process must be highly individualized.

Current imaging techniques make it possible to ascertain the physical development beyond the classical Prader or Quigley staging. Additional pertinent information including gonadal and internal reproductive system development, such as level of urethral-vaginal confluence and completeness and symmetry of internal ductal development, are now emphasized as important pre-operative considerations in all DSD surgeries. This approach provides for better assessment of surgical needs as well as the potential for fertility and sexual function. The use of anogential distance [4], felt to be a good physical index of early fetal androgen exposure, and its relationship to outcome in various DSD diagnoses has been explored but as yet seems to have limited practical usefulness in management of DSD patients.

Current diagnostic criteria remain largely dependent upon hormonal levels. However, improved availability of anti-Mullerian hormone and inhibin B assays enhance the assessment of gonadal development and broader use of liquid-chromotography-tandem mass-spectrometry has led to improved reliability in the measurement of serum steroid concentrations.
This review, which includes only certain aspects regarding the care of those with DSD, has been divided into the following sections: 1) Social issues, 2) Legal issues, 3) Surgical techniques to improve sexual responsiveness and genital appearance, 4) Psychological factors and outcome data, 4) Identification of genetic etiologies of DSD, 5) Gender issues and 7) Brief summaries of active DSD research projects. Similar to the 2006 consensus conference, the aim of this review is to improve the care provided to DSD patients through improvements in diagnostic ability and enhanced collaboration of those different specialties involved in management of DSD patients.

\section{Cultural and social forces shape outcomes in DSD}

Social factors influence outcomes in DSD, although there is limited literature documenting the extent of these effects on management and quality of life. In $\mathrm{CAH}$, poverty, lack of education and inaccessible medical care all exert a negative impact on affected people and their families. These facts are best demonstrated by studies in developing countries, where financial concerns, such as having to buy essential medications at high cost or to travel from far to reach a specialist, constitute primary burdens for affected families [5]. A study performed in a Malaysian tertiary center revealed that approximately one-third of patients with $\mathrm{CAH}$ had poor knowledge of their condition or did not realize that their medications were required to sustain life [6]. Additional issues impacting $\mathrm{CAH}$ families in these countries include lack of newborn screening, which may lead to late diagnosis and gender assignment without appropriate evaluation. Beyond financial disparities, in developed countries, differences in health care delivery models may influence access to care. National health care systems, such as those in Europe, facilitate the implementation of multidisciplinary teams of specialists [7], which is the recommended setting for the care of patients with DSD. While evidence demonstrating the specific benefits of such centralized specialized care in DSD is sparse, data so far indicate improved medical management in $\mathrm{CAH}$ and fewer early genital procedures in DSD when care is rendered by a multidisciplinary team [7-9] although it is not yet clear that these things truly improve outcome.

Religious and cultural factors influence medical decisions and quality of life in CAH. For example, a study from Vietnam recognized that expectations of future marriage and reproduction were main worries of parents with $\mathrm{CAH}$ children [5]. Other cultures in the Middle and Far East favor male over female offspring, and these views have been reported to influence sex assignment in DSD $[10,11]$.

Over the last decade, we have witnessed the growth of many support and advocacy groups. Support groups for $\mathrm{CAH}$ provide information, support and advocacy, and 
have contributed in the development of practice guidelines [12]. The wide application of internet and social media has facilitated the growth of many societies of DSD people all over the world (http://www.isna.org; http://oii.org.au, http://www.caresfoundation.org/, http:// www.aisdsd.org/). These societies, by and large, have challenged the necessity of early genital surgery, advocating for deferral of surgical interventions until the individual is able to give informed consent. Through blogs, advocacy or working with the legislature, these groups have influenced medical and public opinion and shaped policies [13] promoting the rights of individuals with DSD to make their own informed decisions regarding genital surgery. In certain occasions, they have brought legal action against doctors and other officials about early sex assignment surgery that was performed without the consent of the involved child. A number of publications have also been used in the debate about early "genital-normalizing" surgery. A study that has been cited in the media and was even discussed at the Australian Senate is a 2009 Dutch study that examined a physician's personal reactions to the labia minora appearance on their decision to refer or perform surgical reduction. The study found that plastic surgeons were more likely to find larger labia minora "distasteful and unnatural" compared to general practitioners and gynecologists [14]. Although the study does not directly apply to DSD, it has been used extensively to illustrate the biases that can influence clinical decision making, our difficulties to objectively define "normal" genital appearance and to argue against early genital reconstruction. Nevertheless, advocates of early surgery cite potential benefits, while the risk and benefits of such remain to be determined.

Social and cultural controversies around DSD have also extended in the area of sports. Anti-doping screening using serum testosterone measurements currently mandates that levels in females be less than lower limit of normal for males. Such screening led to the diagnosis of $5 \alpha$-reductase type 2 deficiency 46XY DSD in 4 elite young female athletes [15]. These and other highly publicized cases led to revisions of the competition policies set by The International Association of Athletics Federations (IAAF) and International Olympic Committee (IOC). The revised policies recognize the right to privacy but also require that "intersex athletes can be placed in the male and female group on the basis of their legal sex". With the exception of complete androgen insensitivity syndrome (CAIS), DSD individuals with hyperandrogenemia competing as females should undergo treatment to lower testosterone concentration before competition [16]. This policy has been criticized on the grounds of incomplete scientific evidence that endogenous testosterone levels confer athletic advantage in a straightforward or predictable way [17]. Concerns were also expressed on the consequences of the medical procedures used to lower serum testosterone concentration on the overall health of these DSD athletes $[16,17]$.

Overall, today more than ever, there are huge inequalities in the management of DSD disorders dictated by financial and cultural restraints. Clinical practice should take into account not only the medical and psychological situation of the patient, but also the broader cultural environment and its implications for future sexual function and quality of life. Availability of social and specialized mental health services is important and can facilitate this process [18].

\section{Legislative changes and seminal legal cases}

A number of legislative changes regarding sex assignment and intersex status occurred over the last decade worldwide. In this report, we list the ones that attracted media attention and are likely to introduce further policy changes.

In 2012, Argentina passed the "Gender Identity Law", which allows for name and sex changes on official documents without proof of a surgical reconstruction or other medical or psychiatric treatment [19]. Contrary to other states, such as Britain and Spain, where sex changes require the diagnosis of persistent gender dysphoria, the Argentinian law is the first in the world to allow gender reassignment solely based on what the individual proclaims and is applicable to both DSD and transsexual cases. Furthermore, the law grants sex reassignment surgery and hormone therapy as part of public and private health care plans. The year 2013 was marked by many legislative changes establishing the rights of DSD individuals. The Australian Senate passed the Sex Discrimination Amendment (Sexual Orientation, Gender Identity and Intersex Status) Bill 2013 that introduces legislation prohibiting discrimination on the basis of intersex status [13]. The new guidelines on gender recognition state that individuals should be given the option of selecting "male", "female" or "intersex" on their personal documents. In a lengthy report, the Senate committee recommended deferral of early genital surgery until the person can give fully informed consent and proposed state funding of multidisciplinary teams that care for intersex individuals, as well as funding for intersex support groups. In a similar mode, Germany introduced an "indeterminate" sex option on birth certificates (http://www.bbc.com/news/world-europe-24767225), a first in Europe. Although the law does not comment on genital surgery, it gives parents the freedom to choose not to go ahead with early surgery. The law also generated some practical concerns and fear for further discrimination and isolation of people with DSD. As an example, marriage in Germany is only possible between two people legally designated as male and female. While civil partnerships 
involve two people of the same sex, no provisions for the union of an intersex individual are explicitly declared. The same year, the Council of Europe adopted a resolution on the protection of children's rights to physical integrity, demanding that no one be "subjected to unnecessary medical or surgical treatment that is cosmetic rather than vital for health during infancy or childhood" [20]. Although the Council does not clearly define what is "vital for health", a term that can be applied broadly to include multiple somatic and mental elements, it acknowledges the need for further research focused on DSD and support of affected families. Finally, the United Nations Special Rapporteur on Torture included statements regarding management of intersex persons. The report calls upon all states to "repeal any law allowing intrusive or irreversible treatments, including forced genital -normalizing surgery, ...reparative therapies or conversion therapies, when enforced or administered without the free and informed consent of the person concerned". Nevertheless, this has little to do with the nonforced surgeries done in Western civilizations.

In the midst of all these changes, the first lawsuit challenging an early sex assignment surgery on a child with an intersex condition was filed in the United States. The child was diagnosed with ovotesticular DSD and received feminizing genital surgery at 16 months of age. Despite the surgery, the child aged 8 years at the time of the lawsuit, identified as a boy. The adoptive parents, with the assistance of advocate groups, allege that a "medical unnecessary" early genital surgery without the child's consent violated their adopted child's constitutional rights. A federal district court has allowed the case to move forward. In a similar case in Germany, a 46XX $\mathrm{CAH}$ woman sued the surgeon who removed her fullyintact female internal organs when she was 18 years old. In this case, the diagnosis of $\mathrm{CAH}$ was missed until the age of 17, when the presence of uterus and ovaries were discovered during appendectomy. The individual, who identified as a female, was raised as a male and had underdone reconstructive surgery for correction of "hypospadias" as a child. She sought 100,000 euros in damages for pain and suffering, claiming the surgeon failed to inform her about the full extent of the consequences of the operation or about possible alternatives. The court decided in the plaintiff's favor, supporting the need for fully informed consent in sex assignment or sterilization cases.

Over the last decade, we have witnessed an increased awareness and remarkable advances in the rights of people with DSD. Multiple legislative changes in developed countries establish the importance of informed consent in surgical intervention related to DSD. However, some of these decisions may challenge parental authority and ability by providing consent for their child.
Generalized statements about reconstructive surgery in DSD may also hamper a more individualized approach to each case. Since long-term outcome data are limited, some of the recommendations for deferral of surgery until the individual can give full consent can be viewed as lacking medical evidence and may therefore constitute a type of medical experimentation. The need is obvious for long-term outcome research, accurate and fast diagnosis and development of etiology-specific guidelines.

\section{The evolving surgical perspective}

Since the consensus statement on intersex disorders and DSD management published in 2006 [1,2], there continues to be further acceptance of a multi-disciplinary team approach in the medical and surgical management of patients [21,22]. However, the cost of such multidisciplinary team approach must be considered in the context of the value that each institution places on the comprehensive care provided by such a care model.

\section{The evolving surgical perspectives}

Surgery continues to be an accepted treatment for patients born with congenital anomalies such as hypospadias [23] and DSD with ambiguous genitalia [12] along with other functional and cosmetic defects associated with cleft lip and palate, pectus abnormalities, scoliosis, club feet and undescended testes [24]. Evidence-based surgical outcome studies for patients with DSD are inherently difficult to perform secondary to the necessity for long-term follow-up from early childhood to the onset of sexual activity in adolescence and adulthood [25]. Since the 2006 consensus statement progress has been made as a result of more precise understanding of the genital anatomy [26,27], more sophisticated tools to measure surgical and psycho/social outcomes [28,29] and a more accepted approach of increased transparency of the entire medical situation and patient and family inclusiveness during care [21,30,31].

The general consensus for the timing of surgical reconstruction in patients with DSD remains in the first year of life based on family, patient and surgeon preference [32-34]. Solid scientific data, however, supporting this position remains sparse.

Experienced based medicine supports the role of a surgical specialist specifically trained in DSD reconstructive procedures. Surgery for patients with DSD can be divided into either feminizing or masculinizing procedures. Feminizing surgery tends to be slightly more homogenous in that the majority of patients have a diagnosis of congenital adrenal hyperplasia (CAH). In $\mathrm{CAH}$ the endogenous exposure to androgens causes virilization resulting in varying amounts of clitoral enlargement, varying degrees of the labia-urethral folds and labial-scrotal folds (posterior fusion) so that degree of masculinization 
ranges from mild clitoromegaly and posterior fusion to the complete fusion of both sets of labial folds resulting in a urethral extending to the tip of the enlarged clitoris (virtually forming a penis) and fully fusion of the labialscrotal folds forming an (empty) scrotum. Feminizing surgical considerations relate to those along this spectrum toward the more severe. This is in contrast to the rarer patient with an absent vagina and/or clitoris that requires an alternative surgical approach for urogenital sinus reconstruction.

Reconstructive surgery for males with DSD is also more complex in that this population is heterogeneous with respect to both diagnosis and outcome [35,36], so surgery must be individualized based upon the physical development of the genitalia and what is known about etiology and outcome. It continues to be difficult to predict future penile growth potential in boys DSD, particularly among patients with a presumed diagnosis of partial androgen insensitivity syndrome (pAIS). At this time, the sophistication of penile reconstructive surgery remains less advanced than feminizing genitoplasty.

Outcomes for patients with DSD can be measured by psychosocial adaptation; i.e. has the affected individual become a functional member of society, part of a healthy peer group, matriculated school, is employed and has satisfactory relationships. Alternatively, outcomes can focus on surgical reconstruction with specific focus in females on vaginoplasty and clitoroplasty and phalloplasty in males. All would agree that preservation of nerves, erectile tissue and sensitive genital skin is the goal of feminizing genitoplasty surgery. Refinement in technique has included corporal sparing dismembered clitoroplasty [37] and continued efforts to preserve the dorsal nerve of the clitoris by ventral clitoroplasty $[26,38,39]$. Vaginal wall reconstruction has also been improved by the innovative use of previously discarded urogenital sinus tissue [40]. Objective outcome studies have been improved by the use of validated questionnaires [41] and newer technology such as thermal and vibratory sensitivity to measure clitoral and vaginal stimulation [11]. However, the extent of functional improvement of genitoplasty must await long-term evaluation considering anatomy, quality of life, and fertility.

For some situations, the need for vaginoplasty continues to be debated, as, for example, dilation as the treatment of choice for those with vaginal agenesis/ hypoplasia (Rokitansky syndrome) [42]. However, it is clear that such therapy is accompanied with psychological or emotional barriers, even when deferred until the age of approaching sexual activity [43].

There is no question that patients born with DSD have ongoing concerns about surgical results and atypical development of their external genitalia [44]. Noteworthy, however, is that a majority of affected people do not report differences in body image, self-esteem and sexual function despite their congenital anomaly. One longterm study of feminizing genitoplasty showed clear differences in clitoral sensitivity as measured by thermal and vibratory techniques, yet overall sexual function assessed by standard psychosexual outcomes in women with $\mathrm{CAH}$ who received surgery was not significantly different from unaffected counterparts [45]. In a second study, feminizing surgery neither hampered nor improved psychosexual outcome in women with severe virilization [46].

Hence, it is commonly agreed that surgical reconstruction remains a viable option for patients born with ambiguous genitalia to construct functional anatomy. Advances in surgical technique, a better understanding of anatomy and a multidisciplinary, transparent team approach are expected to continue to improve care and surgical outcomes. However, it is essential to follow patients who receive genitoplasty to document short- and long-term cosmetic and functional outcomes to determine the benefits and risks of these procedures.

\section{Reassessment of treatment since the 2006 consensus statement}

The 2006 Consensus Statement recommends that an experienced, multidisciplinary team including members trained in psychology, psychiatry and social work is needed to assist with decisions about gender assignment or reassignment, timing of surgery and sex hormone replacement, and short and long term assessment of outcomes for people with DSD. The 2006 Consensus also states that such specialists may identify maladaptive coping strategies for affected individuals and their families, as well as educate people about their DSD [1,2]. Discussions of the psychological management of DSD increasingly emphasize long-term support that extends beyond gender assignment during the newborn period, to optimize the well-being of patients and their families [47-50]. Additionally, emphasis is now being placed on non-categorical studies of optimal healthcare delivery to, and support of, people with DSD [51]. Included here is a review of publications, since the 2006 Consensus Statement, concerning the evolution of the psychological approach to people affected by DSD.

\section{Gender assignment}

Historically, behavioral sex has been considered binary male or female - and believed to be strongly influenced by genital phenotype, gonadal development and sex chromosomal complement. This view was challenged by John Money's theory of gender in the mid 20th century that purported that gender can be independent of biological sex and influenced by learning as well as biology. At the same time that Money proposed his theory of 
gender, behavioral endocrinologists studying non-human animal models promoted their own theory of brain sex. Specifically, they proposed that masculinization of the nervous system due to androgen exposure during critical periods of development results in male-typic behaviors such as mounting and aggression in species as diverse as rodents, birds and non-human primates [52]. Interestingly, this theory of brain sex promotes the idea that male gender develops in humans as a result of androgen action on the central nervous system, yet the overwhelming majority of investigations conducted by behavioral endocrinologists have been in non-human species that do not clearly exhibit gender.

Most studies of gender outcomes in people with DSD published since the 2006 Consensus Statement continue to show that gender role is masculinized by exposure to early androgens in humans; however, gender identity is less impacted by the prenatal hormone milieu. For some people with DSD, gender identity develops according to sex of rearing [53]. For example, most people who possess a 46,XX sex chromosome complement and are exposed to significant amounts of androgens early in development as a result of having congenital adrenal hyperplasia $(\mathrm{CAH})$ cultivate an interest in hobbies and professions sometimes preferred by males, despite the fact that they are reared female and identify as girls and women [52,54]. A conflicted gender identity is more likely in people with 46,XY DSD and reared female [55]. As already stated, male sex assignment has become increasingly more common in people with 46,XY DSD including prenatal androgenization [56]. Furthermore, recent studies include reports by people with DSD who identify neither as male nor female, or who identify as both male and female at different times in their lives. This inability of binary (male/female) gender categories to adequately describe gender identity is more common in people with DSD who possess a $\mathrm{Y}$ chromosome [54,57].

\section{Timing of surgery}

Genitoplasty has evolved over the last 2 centuries and multiple techniques have been developed to surgically alter the appearance and function of ambiguous genitals $[58,59]$. Parents of children born with genital ambiguity make decisions about whether or not to proceed with various types of genitoplasty for their young child, yet very little is known about how caregivers perceive their child's genital difference or how they make decisions about treatment options. One study of parents revealed that caregivers of boys reported higher depressive symptoms with increasing atypical appearance of their sons' genitals, while caregivers of girls did not [60]. However, these data are correlational and factors other than genital difference may be the actual cause of concern. It is not known if genitoplasty ameliorates parental depression or if people who receive early genitoplasty are more, or less, satisfied with their treatment than those who received later genitoplasty or no surgery at all.

While retrospective evidence for suboptimal cosmetic and functional outcomes of early genitoplasty exists for people born with ambiguous genitalia, some people report satisfaction with the timing of their early surgery [61]. It is not known at this time if these people are representative of DSD individuals overall, nor is it known if preferences for timing of surgery (early, late, never) vary by diagnosis and sex of rearing. Additionally, a majority of surgeons report a preference for performing these procedures in patients younger than 2 years of age [60]. This preference for early treatment, coupled with the fact that data are lacking on outcomes regarding genital cosmesis, sexual function and quality of life for children who do not receive such surgeries [62], contributes to some parents opting for early genitoplasty for their child.

To determine the impact of early clitoroplasty, vaginoplasty and/or phalloplasty on these important outcomes, it is necessary to make comparisons between people with DSD who present with genital ambiguity and receive early surgery, those who present early and receive late surgery, and people with DSD who do not present with ambiguous genitalia and thus do not receive early genitoplasty, and women and men unaffected by DSD. A study by Crouch et al. [29] employed this approach and found that women with $\mathrm{CAH}$ who received clitoroplasty decades earlier reported reduced genital sensitivity and increased sexual dysfunction compared to women with $\mathrm{CAH}$ who did not have clitoral surgery and unaffected women. Another study by Köhler et al. [63] reported high rates of dissatisfaction with cosmetic outcome in both women and men following genitoplasty; however, men reported greater satisfaction than women in terms of functional outcomes of their genitals. Women who received in excess of 2 genital surgeries reported more dissatisfaction with clitoral arousal and their overall sex life, but not with sexual problems or cosmetic and functional outcomes of genitoplasty, compared to women who received fewer than 2 surgeries. Women with 46,XY DSD who never received genitoplasty as a result of being born with female-typical external genitalia were mostly satisfied with their vaginal length and clitoral arousal, yet these women reported more problems with sexual desire and arousal, dyspareunia and vaginimus than unaffected women. Due to the small sample size, it was not possible to compare functional outcomes of male genitoplasty for the men included in this study [63].

Ample evidence exists that genitoplasty procedures performed in the past resulted in less than optimal cosmetic and functional results for many people. While prospective evaluation of modern surgical approaches to 
genital ambiguity provides some information on shortterm cosmetic outcome and urinary function [64], data on sexual function are absent. Factors other than genital surgery may contribute to decreased quality of life and sexual problems in people with DSD [65]. For example, men with $\mathrm{CAH}$ due to 21-hydroxylase deficiency are born with typical genitalia yet they report less sexual activity than unaffected men [66]. As we await results from prospective studies of modern genitoplasty procedures, the current state of deciding on the place for early genitoplasty in DSD medical care was recently summarized by Creighton et al. [62].

"At present, parents have the right to decide if their child should or should not have genital surgery in infancy or childhood. It is important to adopt a respectful and non-blaming stance when considering parental decisions to take care of their child as best they can, in uniquely difficult circumstances. Some surgeons are realizing that one approach does not fit all. Opponents to surgery may equally consider the possibility that one criticism does not fit all. If we were to successfully lobby for and contribute to greater resources to educate and support parents, surgery may be better targeted for families for whom it is indicated" [62].

\section{Patient/caregiver education}

In a study of posttraumatic stress symptoms (PTSS) among parents of children with DSD, confusion and uncertainty about what caused their child's DSD and how to proceed with medical treatment were the clearest predictors of stress [67]. Other studies of parents and affected people reveal that major concerns include how to share information about their child's or their own diagnosis with others while maintaining privacy $[68,69]$. Thus, there is increasing understanding in the medical community that people with DSD and their caregivers should be educated about their condition; however, evidence is lacking on how, when and by whom this type of information should be delivered [70,71]. Roen and Pasterski [72] describe the importance of prospectively collecting information about DSD disclosure so that patient/caregiver education can be both optimized and evidence-based.

In an editorial accompanying a special issue of Psychology \& Sexuality on new developments in understanding DSD, Liao and Roen [49] ask how psychological research and practice can most usefully contribute to the field. This is a new way of thinking about behavioral aspects of DSD as previous psychological thought has almost exclusively centered on brain masculinization via hormonal and/or genetic mechanisms as well as the implications of such masculinization on gender assignment.

\section{Strategies to ameliorate maladaptive coping and improve QoL}

Affected individuals and their families benefit from having a clear and thorough understanding of DSD and associated treatment options, and also by interacting with other people who have similar medical and life experiences [50]. For example, advice on how to respect a child's privacy concerning their DSD without attaching a sense of shame is a real challenge faced by many caregivers [71]. Peer support can provide DSD-specific information by people who have "first-hand" knowledge of these conditions and associated treatments, as well as reduce isolation that often accompanies a diagnosis that is both rare and complex [73]. People with DSD including gender dysphoria, or dissatisfaction with their sex of rearing, may benefit from more structured psychosocial support provided by mental health professionals [65].

Some experiences of maladaptive coping and poor QoL result from experiences with medical and/or surgical treatments per se, and are not a direct result of having a particular DSD. For example, over-treatment with corticosteroids is associated with anxiety and sexual dissatisfaction in men with $\mathrm{CAH}$; therefore, optimizing medical management for 46,XX DSD due to 21-hydroxylase deficiency is expected to improve coping and QoL for affected women [62]. Additionally, many women with $\mathrm{CAH}$ who received feminizing genitoplasty when they were infants are dissatisfied with the long-term cosmetic and functional outcomes of these surgeries that were originally meant to reduce stigma [73]. Whether or not modern surgical approaches to genitoplasty result in improved outcomes and greater patient satisfaction has yet to be determined. In addition to optimizing medical and surgical treatments specific to DSD, addressing and ameliorating the burdens associated with having a chronic medical condition throughout development using a patient- and family-centered approach is expected to result in improved outcomes. Further research is needed to establish evidence-based guidelines for best practices in the delivery of psychosocial, endocrine and surgical care for people with DSD.

\section{Summary of the psychological approach to DSD}

Prior to the 2006 Consensus, psychological approaches to DSD focused on understanding brain masculinization via genetic and hormonal mechanisms, and its implications for gender assignment and development. Since the Consensus, focus has shifted to optimizing long-term well-being of people with DSD and their caregivers. To accomplish this optimization, studies are needed to determine how, when and by whom education about, and support for, DSD can best be delivered [50]. This newer, non-categorical psychological approach to DSD mirrors what occurs in other chronic illnesses of childhood. 


\section{Recent progresses in the genetic diagnosis of DSD}

The traditional approach for diagnosis of patients with a DSD has been, until recently, to assess the patient's phenotype rigorously, including physical examination of the external genitalia, imaging of the internal reproductive structures, endocrine assessment in basal and stimulated states, and eventually, once the differential diagnosis has been narrowed down, molecular analysis of a small number of specific genes known to cause DSD.

The wide availability and decreasing prices of new genomic technologies is slowly changing this approach, as a genetic investigation is more often initiated early in the diagnostic process. Two main methodologies have made this possible. One is Chromosomal Microarray, which allows the detection of Copy Number Variants (CNVsmicrodeletions and microduplications as small as $50 \mathrm{~kb}$ on a clinical basis). In two studies examining a large number of patients with DSD (116 and 23, respectively), CNVs were identified in $13 \%$ to $21.5 \%$ of the cases, providing an important diagnostic clue $[74,75]$. The second, more recent technology is Whole Exome Sequencing (WES) that allows for the sequencing of all the exons (the coding parts of the genes) of the entire genome. This approach detects genetic variants at the highest possible level of resolution (mutations of 1 base pair) and is changing the diagnostic landscape. It allows not only for the detection of mutations in all known DSD genes (avoiding multiple, geneby-gene analyses), but also opens the door to identifying clinically significant variants in novel DSD genes [76].

The potential benefits of this new genetic diagnostic tool, from the patients' perspective, include a shortcut to the "diagnostic odyssey" often experienced by families, improved genetic counseling and understanding of reproductive options for the family, improved monitoring (identification of associated risks, guide to natural history of the condition), and a cathartic effect (finality of diagnosis, explanation of the condition, less uncertainty allowing to move forward).

There are still remaining challenges with WES, including the availability of a Trio (both parents and the patients, allowing for better interpretation of genetic variants), the choice of reporting of genetic variants on a clinical basis, including variants of uncertain clinical significance and incidental or secondary findings unrelated to the primary condition, and the turn around time that remains long (up to 3 months, but with indications that it could rapidly go down to 4-6 weeks).

Overall, the combined use of CMA and WES is already changing our diagnostic approach to patients with DSD.

\section{Consideration of gender issues of DSD and transgender patients}

The issues of sex assignment/sex or gender reassignment in the context of DSD are the most complex and challenging. Although issues related to gender identity are an important dimension to the care of both DSD and transgender patients, there are enough dissimilarities between the medical needs of these populations to warrant separate multi-disciplinary clinical programs at some centers. Attention needs to be paid to the differences in age of presentation and medical histories [77]. However, there are some considerations regarding gender identity that are common to both DSD and transgender populations: a) While sex is typically "assigned" at birth, gender identity assignment can only be implied, and not, in fact, known until an individual achieves a particular level of psychological development and selfawareness, b) DSD patients can be assigned a sex of rearing based on the current best prediction of what is likely to be a person's gender identity, c) Gender identity is understood to reflect a complex interplay of biological, environmental, and cultural factors, and it is impossible to predict gender identity with certainty-whether or not a person has a DSD. d) Mental health instruments are in use in some centers; exist and are in use in a number of programs such as the Utrecht Gender Dysphoria Scale and the Body Image Scale [78]. However, because of inadequacies, these may not capture a person's true gender identity, and the development of new or modified assessment tools appears to be necessary. e) A study of gender dysphoric adolescents (without a DSD) indicates that some mental health co-morbidities markedly improve with an approach that affirms the expressed or experienced gender [76]. f) Given that one of the most daunting tasks of the DSD team is assigning a sex of rearing based on a best prediction of what a person's gender identity is likely to be, further research into understanding the underpinnings of gender is needed. More follow-up studies are also needed to determine the how factors leading to gender align with the development of a person's gender identity.

\section{Currently active DSD research studies and recent meeting \\ Comprehensive european clinical outcome study (Birgit Kohler)}

dsd-LIFE is a comprehensive European clinical outcome study investigating the long-term outcome of adults with the various conditions included in the umbrella term disorders of sex development (DSD). The aim of the study is to improve treatment and care and to develop clinical guidelines for care of individuals with DSD. Moreover, information about DSD will be disseminated to the general public in Europe.

dsd-LIFE investigates health related quality of life (HRQoL), psychological well-being, social participation, patients' views, experiences with care and support, satisfaction with hormone treatment, surgery and psychological 
support, effects of hormone therapies on general health, psychosexual and ethical issues in individuals $>=16$ years with DSD. Involved in the study are patients with a diagnosis according the actual DSD classification: 1. individuals with numeric sex chromosome aberrations such as 45 , $\mathrm{XO} / 46, \mathrm{XY}, 46, \mathrm{XX} / 46, \mathrm{XY}, 47, \mathrm{XXY}, 45, \mathrm{X}$ and mosaicism. 2. individuals with XY DSD such as complete and partial forms of testicular dysgenesis, disorders of androgen synthesis e.g. 5alpha-reductase II and 17beta-hydroxysteroid dehydrogenase (HSD) 3 deficiency, defects of androgen action such as complete and partial androgen insensitivity syndrome (CAIS, PAIS) and unclassified hypospadias. 3. individuals with XX DSD such as ovarian dysgenesis and congenital adrenal hyperplasia (CAH).

The study is performed by a European consortium of 14 centers offering multidisciplinary care for patients with DSD and one ethics center in Germany, France, the Netherlands, United Kingdom, Sweden and Poland. All study centres are in close contact with national patient support groups.

The data of dsd-LIFE will be included in clinical guidelines for care of DSD. The different needs of the various condition covered by the umbrella term DSD will be considered in development of the guidelines. The expected long-term impact of the study is improvement of clinical care, higher quality of life and better integration and participation of individuals with DSD in society. The dsd-LIFE project is funded by the European Union (FP7, grant number 305373, 2012-2016). More details about dsd-LIFE can be found on the website: http://www.dsd-life.eu.

\section{The International DSD (I-DSD) Registry - a platform for international cooperation in research and clinical practice: Jillian Bryce, S. Faisal Ahmed}

Effective clinical care and research in DSD, as well as assessment of long-term outcome of these rare conditions, requires multicenter collaboration across national boundaries and across multiple clinical and research disciplines. Following the publication of the 2006 Consensus, the ESPE Research Unit supported a small group of investigators in 2007 to develop a prototype registry which was subsequently funded by EUFP7 as part of the EuroDSD collaboration from 2008 to 2011. Currently, the Registry which adheres to the highest standards of data governance and security is supported by the MRC as the I-DSD Registry (www.i-dsd.org). The Registry is managed by a project management group and has a steering committee and continues to undergo revisions that are enhancing its functionality as desired in the last survey of its users in 2013.

In April 2014, there were 1340 cases added by registered users from 33 centers in 20 countries across 4 continents. A further 70 centers and 24 countries have registered as users covering all 6 habitable continents.
The age of presentation of cases in the Registry ranges from $<1$ month to 53 years, with a median age of presentation of 1-3 months. The median year of birth is 1998 (range 1927-2013). The most common conditions include disorders of androgen action (377) followed by disorders of gonadal development (298). The majority of cases had a 46XY karyotype (957), followed by a 46XX karyotype (249). Around 56\% (753) cases in the Registry have a female sex and $44 \%$ (586) have a male sex. In addition to clinical data, biological specimens are available from the clinical users in 40\% (536) cases.

Although the primary objective of the I-DSD Registry is to improve the standard of research that has a clinical impact, the Registry also acts as a basis for exchanging knowledge and experience on rare conditions. More recently, the Registry has created a mirror site, I-CAH (www.i-cah.org) for children and adults with congenital adrenal hyperplasia. I-DSD will also support the next International DSD Symposium which will be held in Ghent, Belgium between from the 11th to the 13th June 2015.

\section{The disorders of sex development - Translational Research Network (DSD-TRN) -David Sandberg, Eric Vilain}

TRN [79] is an NICHD-supported network, currently comprising seven U.S. medical centers, delivering interdisciplinary healthcare services to patients with DSD and their families following the principles of care outlined in the 2006 Consensus Statement [1,2]. The objectives of this patient registry-based learning collaborative include:

1. Identification of novel genetic mechanisms of sex development and improved understanding of the pathophysiology and molecular diagnosis of DSD.

2. Development of standardized tools for reliable phenotypic descriptions across multiple network sites and investigators, including radiological, biochemical, histological evaluations and descriptions of genital phenotype and postsurgical appearance and function, facilitating interpretation of genetic, gender, psychosocial and quality of life outcomes.

3. Identification of short and medium-term outcomes by delivering a comprehensive psychosocial and health-related quality of life assessment battery using psychometrically robust measures suitable for use in routine clinical care; a necessary step leading to evidence-based psychosocial treatment protocols.

4. Building a sustainable clinical research infrastructure ensuring rapid translation of new evidence into ongoing clinical practice by integrating standardized DSD diagnostic and treatment protocols and 
fostering the transfer of best practices in healthcare delivery across network sites. This registry provides the analytic platform by which data are collected, analyzed, and shared among researchers and sites, while a collaborative network supplies the foundation for multidisciplinary basic, translational and clinical research.

In contrast to other DSD patient registries (eg, I-DSD [80], primarily created to help researchers identify a sufficient number of patients for recruitment to studies, the DSD-TRN is designed to capture the "process" of ongoing care using a comprehensive combination of prospectively applied genetic, phenotypic and psychosocial approaches to inform clinical management of the individual patient and family. A descriptive approach that examines patient outcomes as a function of variability in patient diagnosis, individual and family characteristics, and features of clinical care has been effectively implemented in other rare diseases (eg, cystic fibrosis [81]) to systematically improve outcomes.

The DSD-TRN also serves as a platform for hypothesisdriven research by creating a clinical network that can adopt research protocols that are either integrated into the model of care (eg, a decision support tool study [82] or piloting the value of standardizing medical photography in DSD [83]) or conducted as stand-alone projects conducted in parallel to ongoing care (eg, functional studies of newly identified genetic variants [84]).

The DSDTRN incorporates the unique and valuable input from patient advocacy and support groups through collaboration of the Advocacy Advisory Network (AAN), a consortium of DSD patient advocacy and support organizations. Input of the AAN regarding network priorities and through involvement in collaborative projects is coordinated by Accord Alliance [85] a not-for-profit created to serve as a convener of all stakeholders involved in optimizing health care and quality of life outcomes for persons affected by DSD and their families.

\section{Short-term outcomes of genitoplasty - Amy Wisniewski, Larry Mullins}

This is an NIH-funded, prospective study of the shortterm outcomes of feminizing or masculinizing surgeries for children ( $<2$ yr old) born with ambiguous genitalia. Included in this project are studies of how parents make decisions about if, and when, to have genitoplasty for their child, as well as the incidence of decisional regret after the fact. This project includes investigators from 11 children's hospital across the U.S.. At the conclusion of this study it will be known: (1) if parents are as satisfied with the cosmetic outcomes of their child's genitoplasty as surgeons who perform these procedures, (2) which surgical procedures are associated with the lowest complication rates, (3) the frequency of urinary tract infections prior to and following genitoplasty, and (4) the frequency of decisional regret by parents following their child's genitoplasty. The studies in this multi-institutional project will provide much needed information regarding the risks and benefits of modern genitoplasty procedures as well as the impact of these decisions on parents.

\section{Growing up with DSD: critical development of issues for children and families affected by disorders of sex development}

This meeting was held at the National Institutes of Health Campus in Bethesda, Maryland on MARCH 26-27, 2014 to inform and assess the needs for basic research and research into the care of DSD patients and their families.

\section{Summary}

Since the 2006 consensus statement almost a decade ago, changes in the diagnostic approach and management of DSD patients have been driven by challenges from legal and ethical perspectives from advocacy and support groups. Hence, these are summarized first in this up-date. While methods for assessment and outcome studies are progressing, there has not been substantial progress in that realm. Although surgical techniques continue to improve, the primary challenge in the area involves the complex questions as to whether and when genital and gonadal surgery should be done to best enhance gender development and quality of life for those involved. Hopefully this summary will provide a basis for further evaluation and collaboration so that an objective perspective of what care best benefits the patient and families can be determined.

\section{Competing interests}

$\mathrm{PL}$, LB, MGV, SR and $\mathrm{CH}$ have no competing interests. AW holds an $\mathrm{NIH}$-funded, prospective study of the short-term outcomes of feminizing or masculinizing surgeries for children ( $<2$ yr old) born with ambiguous genitalia. EV and SR are investigators for the NICHD network project entitled "The Disorders of Sex Development - Translational Research Network.

\section{Authors' contributions}

All authors participated in the literature review. PAL, AW and $\mathrm{CH}$ participated in the determination of topics to be included, outline of the manuscript and invitation to contributors, writing of the introduction and summary sections and assembly of the manuscript. AW also authored the initial section on "Reassessment of Treatment since the 2006 Consensus Statement". LB authored the initial section on "The Evolving Surgical Perspective". MGV authored the initial section on "Cultural and social forces shape outcome in DSD". EV initially authored the section on "Recent progress in the genetic diagnosis of DSD". SR initially authored the section on "Consideration of Gender Issues of DSD and Transgender Patients". All authors read and approved the final manuscript.

\section{Acknowledgements}

Acknowledgement and Appreciation to express to the following individuals for contributions to this manuscript: S. Faisal Ahmed, Developmental Endocrinology Research Group, School of Medicine and Royal Hospital for Sick Children, 
Glasgow, UK; Jillian Bryce, Research Support Manager, University of Glasgow Research Institute, Glasgow, UK; Patricia Fechner, Department of Pediatrics, University of Washington School of Medicine, Seattle, WA; Birgit Kohler-Institute for Experimental Pediatric Endocrinology, Charite Hospital, Berlin, Germany; Larny Mullins, Pediatrics and Health Psychology Research Laboratory, Oklahoma State University, Stillwater, OK; David Sandberg, Department of Pediatrics, University of Michigan Medical School, Ann Arbor, Ml.

\section{Author details \\ 'Department of Pediatrics, Penn State Hershey Medical Center, The Milton S. Hershey Medical Center, 500 University Drive, PO Box 850, Hershey, PA 17033, USA. ${ }^{2}$ Department of Urology, University of Oklahoma College of Medicine, Oklahoma City, OK, USA. ${ }^{3}$ Pediatric Urology, University of California San Francisco, San Francisco, CA, USA. ${ }^{4}$ Division of Pediatric Endocrinology Weill Cornell Medical College, New York, NY, USA. ${ }^{5}$ Departments of Human Genetics, Pediatrics, and Urology, University of California Los Angeles, Los Angeles, CA, USA. ${ }^{6}$ Department of Pediatrics, University of California San Francisco, San Francisco, CA, USA. ${ }^{7}$ Medical College of Georgia, 1120 15th St, Augusta, GA 30912, USA.}

Received: 13 June 2014 Accepted: 18 July 2014

Published: 15 September 2014

\section{References}

1. Lee PA, Houk CP, Ahmed SF, Hughes IA and the International Consensus Conference on Intersex Working Group: Consensus statement on management of intersex disorders. Pediatrics 2006, 118:e488-e500.

2. Hughes IA, Houk C, Ahmed SF, Lee PA, LWPES Consensus Group, ESPE Consensus Group: Consensus statement on the management of intersex disorders. Arch Disease Child 2006, 91:554-563.

3. Diamond DA, Burns JP, Huang L, Rosoklija I, Retik AB: Gender assignment for newborns with 46XY cloacal exstrophy: a 6-year followup survey of pediatric urologists. J Urol 2011, 186(4 Suppl):1642-1648. doi:10.1016/j. juro.2011.03.101.

4. Hsieh MH, Eisenberg ML, Hittelman AB, Wilson JM, Tasian GE, Baskin LS: Caucasian male infants and boys with hypospadias exhibit reduced anogenital distance. Hum Reprod 2012, 6:1577-1580.

5. Armstrong KL, Henderson C, Hoan NT, Warne GL: Living with congenital adrenal hyperplasia in Vietnam: a survey of parents. J Pediatr Endocrinol Metab 2006, 10:1207-1223.

6. Zainuddin AA, Grover SR, Shamsuddin K, Mahdy ZA: Research on quality of life in female patients with congenital adrenal hyperplasia and issues in developing nations. J Pediatr Adolesc Gynecol 2013, 6:296-304. doi:10.1016/ j.jpag.2012.08.004

7. Pasterski V, Prentice P, Hughes IA: Consequences of the Chicago consensus on disorders of sex development (DSD): current practices in Europe. Arch Dis Child 2010, 8:618-623. doi:10.1136/adc.2009.163840

8. Schaeffer TL, Tryggestad JB, Mallappa A, Hanna AE, Krishnan S, Chernausek SD, Chalmers $\sqcup$, Reiner WG, Kropp BP, Wisniewski AB: An evidence-based model of multidisciplinary care for patients and families affected by classical congenital adrenal hyperplasia due to 21-hydroxylase deficiency. Int J Pediatr Endocrinol 2010, 2010:692439.

9. Parisi MA, Ramsdell LA, Burns MW, Carr MC, Grady RE, Gunther DF, Kletter GB, McCauley E, Mitchell ME, Opheim KE, Pihoker C, Richards GE, Soules MR, Pagon RA: A gender assessment team: experience with 250 patients over a period of 25 years. Genet Med 2007, 6:348-357.

10. Uslu R, Oztop D, Ozcan O, Yilmaz S, Berberoğlu M, Adiyaman P, Cakmak M, Kerimoğlu E, Ocal G: Factors contributing to sex assignment and reassignment decisions in Turkish children with 46, XY disorders of sex development. J Pediatr Endocrinol Metab 2007, 9:1001-1015.

11. Bhansali A, Walia R, Sing R, Sriram M, Rao K, Dhaliwal L, Dutta P: Disorders of Sex development: a study of ninety-five patients. Endocrinologist 2009, 9:98-101.

12. Auchus RJ, Witchel SF, Leight KR, Aisenberg J, Azziz R, Bachega TA, Baker LA, Baratz AB, Baskin LS, Berenbaum SA, Breault DT, Cerame BI, Conway GS, Eugster EA, Fracassa S, Gearhart JP, Geffner ME, Harris KB, Hurwitz RS, Katz AL, Kalro BN, Lee PA, Alger Lin G, Loechner K, Marshall I, Merke DP, Migeon C, Miller WL, Nenadovich TL, Oberfield SE, et al: Guidelines for the development of comprehensive care centers for congenital adrenal hyperplasia: guidance from the CARES foundation initiative. Int J Pediatr Endocrinol 2010, 2010:275213. doi:10.1155/2010/275213.
13. Commonwealth of Australia. http://www.aph.gov.au/Parliamentary_Business/ Bills_Legislation.

14. Reitsma W, Mourits MJ, Koning M, Pascal A, van der Lei B: No (wo)man is an island-the influence of physicians' personal predisposition to labia minora appearance on their clinical decision making: a cross-sectional survey. J Sex Med 2011, 8:2377-2385.

15. Fénichel P, Paris F, Philibert P, Hiéronimus S, Gaspari L, Kurzenne JY, Chevallier P, Bermon S, Chevalier N, Sultan C: Molecular diagnosis of 5a-reductase deficiency in 4 elite young female athletes through hormonal screening for hyperandrogenism. J Clin Endocrinol Metab 2013, 98:E1055-E1059. doi:10.1210/jc.2012-3893.

16. Xavier NA, McGill JB: Hyperandrogenism and intersex controversies in women's olympics. J Clin Endocrinol Metab 2012, 97:3902-3907. doi:10.1210/jc.2012-2792.

17. Karkazis K, Jordan-Young R, Davis G, Camporesi S: Out of bounds? A critique of the new policies on hyperandrogenism in elite female athletes. Am J Bioeth 2012, 12:3-16. doi:10.1080/15265161.2012.680533. Erratum in: Am J Bioeth. 2012;12(10):56.

18. Meyer-Bahlburg HF: Gender monitoring and gender reassignment of children and adolescents with a somatic disorder of sex development. Child Adolesc Psychiatr Clin N Am 2011, 20:639-649. doi:10.1016/j. chc.2011.07.002.

19. New York Times. http://www.nytimes.com/2012/05/25/world/americas/ transgender-advocates-hail-argentina-law.html.

20. Council of Europe: Resolution 1952 (2013). Children's right to physical integrity. 2013, http:/assembly.coe.int/nw/xml/XRef/Xref-XML2HTML-en.asp?

21. Houk CP, Lee PA: Update on disorders of sex development. Curr Opin Endocrinol Diabetes Obes 2012, 1:28-32. PubMed PMID: 22157406.

22. Creighton S, Chernausek SD, Romao R, Ransley P, Salle JP: Timing and nature of reconstructive surgery for disorders of sex development introduction. J Pediat Urol 2012, 6:602-610. PubMed PMID: 23146296.

23. Baskin LS, Ebbers MB: Hypospadias: anatomy, etiology, and technique. J Pediat Surg 2006, 3:463-472. PubMed PMID: 16516617.

24. Arnold G, Coran AC, Scott Adzick N, Krummel TM, Laberge J-M, Shamberger R, Caldamone A: Pediatric Surgery. 7th edition. London: Elsivier; 2012 Mosby edition.

25. Lee P, Schober J, Nordenstrom A, Hoebeke P, Houk C, Looijenga L, Manzoni G, Reiner WW: Review of recent outcome data of disorders of sex development (DSD): emphasis on surgical and sexual outcomes. J Pediat Urol 2012, 6:611-615. PubMed PMID: 23158651.

26. Kalfa N, Liu B, Cao M, Vilella M, Hsieh M, Baskin LS: 3-dimensional neuroanatomy of the human fetal pelvis: anatomical support for partial urogenital mobilization in the treatment of urogenital sinus. $J$ Urol 2008, 180(4 Suppl):1709-1714. discussion 14-5. PubMed PMID: 18708223.

27. Schober J, Cooney T, Pfaff D, Mayoglou L, Martin-Alguacil N: Innervation of the labia minora of prepubertal girls. J Pediat Adol Gynec 2010, 23:352-357. PubMed PMID: 20493733

28. Wilson JM, Arnhym A, Champeau A, Ebbers M, Coakley F, Baskin L: Complete androgen insensitivity syndrome: an anatomic evaluation and sexual function questionnaire pilot study. J Pediat Urol 2011, 7:416-421. PubMed PMID: 20719566.

29. Crouch NS, Liao LM, Woodhouse CR, Conway GS, Creighton SM: Sexual function and genital sensitivity following feminizing genitoplasty for congenital adrenal hyperplasia. J Urol 2008, 179:634-638. PubMed PMID: 18082214.

30. Palmer BW, Wisniewski AB, Schaeffer TL, Mallappa A, Tryggestad JB, Krishnan S, Chalmers LJ, Copeland K, Chernausek SD, Reiner WG, Kropp BP: A model of delivering multi-disciplinary care to people with 46 XY DSD. J Pediat Urol 2012, 8:7-16. PubMed PMID: 22078657

31. Sandberg DE, Gardner M, Cohen-Kettenis PT: Psychological aspects of the treatment of patients with disorders of sex development. Semin Reprod Med 2012, 30:443-452. PubMed PMID: 23044882. Pubmed Central PMCID: 3687360

32. Wisniewski AB, Migeon CJ, Malouf MA, Gearhart JP: Psychosexual outcome in women affected by congenital adrenal hyperplasia due to 21-hydroxylase deficiency. J Urol 2004, 171:2497-2501. PubMed PMID: 15126884.

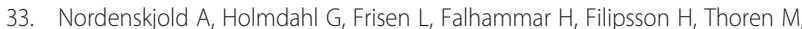
Janson PO, Hagenfeldt K: Type of mutation and surgical procedure affect long-term quality of life for women with congenital adrenal hyperplasia. J Clin Endocrinol Metab 2008, 93:380-386. PubMed PMID: 18029470. 
34. Yankovic F, Cherian A, Steven L, Mathur A, Cuckow P: Current practice in feminizing surgery for congenital adrenal hyperplasia; A specialist survey. J Pediat Urol 2013, 9:1103-1107. PubMed PMID: 23693144.

35. Massanyi EZ, Dicarlo HN, Migeon CJ, Gearhart JP: Review and management of 46, XY disorders of sex development. J Pediat Urol 2013, 9:368-379. PubMed PMID: 23276787

36. Schonbucher V, Schweizer K, Rustige L, Schutzmann K, Brunner F, RichterAppelt $\mathrm{H}$ : quality of life of individuals with 46, XY disorders of sex development. J Sex Med 2012, 9:3154-3170. PubMed PMID: 20059666.

37. Pippi Salle JL, Braga LP, Macedo N, Rosito N, Bagli D: Corporeal sparing dismembered clitoroplasty: an alternative technique for feminizing genitoplasty. J Urol 2007, 178:1796-1800. discussion 801. PubMed PMID: 17707426.

38. Poppas DP, Hochsztein AA, Baergen RN, Loyd E, Chen J, Felsen D: Nerve sparing ventral clitoroplasty preserves dorsal nerves in congenital adrenal hyperplasia. J Urol 2007, 178(4 Pt 2):1802-1806. discussion 6. PubMed PMID: 17707008.

39. Baskin LS, Erol A, Li YW, Liu WH, Kurzrock E, Cunha GR: Anatomical studies of the human clitoris. J Urol 1999, 162:1015-1020. PubMed PMID: 10458423.

40. Rink RC, Cain MP: Urogenital mobilization for urogenital sinus repair. BJU Int 2008, 102:1182-1197. PubMed PMID: 19035913.

41. Fagerholm R, Mattila AK, Roine RP, Sintonen H, Taskinen S: Mental health and quality of life after feminizing genitoplasty. J Pediat Surg 2012, 47:747-751. PubMed PMID: 22498391.

42. Routh JC, Laufer MR, Cannon GM Jr, Diamond DA, Gargollo PC: Management strategies for Mayer-Rokitansky-Kuster-Hauser related vaginal agenesis: a cot-effectiveness analysis. J Urol 2010, 184:2116-2121.

43. Liao L, Doyle J, Crouch NS, Creighton SM: Emotional and J wellness and quality of life in women with Rokitansky syndrome. Am J Obstet Gynecol 2011, 205:117 e1-6.

44. van der Zwan YG, Janssen EH, Callens N, Wolffenbuttel KP, Cohen-Kettenis PT, van den Berg M, Drop SL, Dessens AB, Beerendonk C, Dutch Study Group on DSD: Severity of virilization is associated with cosmetic appearance and sexual function in women with congenital adrenal hyperplasia: a cross-sectional study. J Sex Med 2013, 10:866-875. PubMed PMID: 23237191

45. Lesma A, Bocciardi A, Corti S, Chiumello G, Rigatti P, Montorsi F: Sexual function in adult life following passerini-glazel feminizing genitoplasty in patients with congenital adrenal hyperplasia. J Urol 2014, 191:206-211. PubMed PMID: 23933397.

46. Callens N, van der Zwan YG, Drop SL, Cools M, Beerendonk CM, Wolffenbuttel KP, Dessens AB: Do surgical interventions influence psychosexual and cosmetic outcomes in women with disorders of sex development? ISRN Endocrinol 2012, 2012:276742. PubMed PMID: 22462013. Pubmed Central PMCID: 3313564.

47. Ahmed SF, Gardner M, Sandberg DE: Management of children with disorders of sex development: new care standards explained. Psychol Sexual 2014, 5:5-14.

48. Brain CE, Creighton SM, Mushtaq I, Carmichael PA, Barnicoat A, Honour JW, Larcher V, Achermann JC: Holistic management of DSD. Best Pract Res Clin Endocrinol Metab 2010, 24:335-354.

49. Liao LM, Roen K: Intersex/DSD post-Chicago: new developments and challenges for psychologists. Psychol Sexual 2014, 5:1-4.

50. Liao LM, Simmonds M: A values-driven and evidence-based health care psychology for diverse sex development. Psychol Sexual 2014, 5:83-101.

51. Sandberg DE, Mazur T: A Noncategorical Approach to the Psychosocial Care of Persons With DSD and Their Families. In Gender Dysphoria and Disorders of Sex Development: Progress in Care and Knowledge. Edited by Kreukels BPC, Steensma T, de Vries ALC. New York: Springer; 2014, Chapter 5, pages 93-114

52. Meyer-Bahlburg HFL: Sex steroids and variants of gender identity. Endocrinol Metab Clin N Am 2013, 42:435-452.

53. Jürgensen $M$, Kleinemeier $E$, Lux A, Steensma TD, Cohen-Kettenis PT, Hiort O, Thyen U, Kökler B, the DSD Network Working Group: Psychosexual development in adolescents and adults with disorders of sex development - results from the German clinical evaluation study. J Sex Med 2013, 10:2703-2714.

54. Schweizer K, Brunner F, Handford C, Richter-Appelt H: Gender experience and satisfaction with gender allocation in adults with diverse intersex conditions (divergences of sex development, DSD). Psychol Sexual 2014, 5:83-101.

55. Mattila AK, Fagerholm R, Santtila P, Miettinen PJ, Taskinen S: Gender identity and gender role orientation in female assigned patients with disorders of sex development. J Urol 2012, 2013(188):1930-1934.

56. Lee PA, Houk CP: Key discussions from the working party on Disorders of Sex Development (DSD) evaluation, Foundation Merieux, Annecy, France, March 14-17, 2012. Int/ J Ped Endo 2013, 2013(1):12.

57. Ercan O, Kutlug S, Uysal O, Alikasifoglu M, Inceoglu D: Gender identity and gender role in DSD patients raised as females: a preliminary outcome study. Front Endocrinol 2013, 4:86. doi:10.3389/fendo.2013.00086.

58. Braga LH, Salle JLP: Congenital adrenal hyperplasia: a critical appraisal of the evolution of feminizing genitoplasty and the controversies surrounding gender assignment. Eur J Pediatr Surg 2009, 19:203-210.

59. Hurwitz: Feminizing surgery for disorders of sex development: Evolution, complications and outcomes. Curr Urol Rep 2011, 12:166-172.

60. Wolfe-Christensen C, Fedele DA, Kirk K, Phillips TM, Mazur T, Mullins LL, Chernausek SD, Lakshmanan Y, Wisniewski AB: Degree of external genital malformation at birth in children with a disorder of sex development and subsequent caregiver distress. J Urol 2012, 188:1596-1600.

61. Fagerholm R, Santtila P, Miettinen PJ, Mattila A, Rintala R, Taskinen S: Sexual function and attitudes toward surgery after feminizing genitoplasty. J Urol 2011, 2011(185):1900-1904.

62. Creighton SM, Michala L, Mushtaq I, Yaron M: Childhood surgery for ambiguous genitalia: glimpses of practice changes or more of the same? Psychol Sexual 2013, 2014(5):34-43. doi:10.1080/19419899.2013.831214.

63. Köhler B, Kleinemeir E, Lux A, Hiort O, Grüters A, Thyen U and the DSD Network Working Group (2012): Satisfaction with genital surgery and sexual life of adults with $\mathrm{XY}$ disorders of sex development: results from the German clinical evaluation study. J Clin Endocrinol Metab 2012, 97:577-588

64. Braga LHP, Lorenzo AJ, Tatsuo ES, Silva IN, Salle JLP: Prospective evaluation of feminizing genitoplasty using partial urogenital sinus mobilization for congenital adrenal hyperplasia. J Urol 2006, 176:2199-2204.

65. Jürgensen M, Lux A, Benedikt Wien S, Kleinemeier E, Hiort O, Thyen U: Health-related quality of life in children with disorders of sex development (DSD). Eur J Pediatr 2014, 2014(173):893-903.

66. Falhammar H, Nyström HF, Thorén M: Quality of life, social situation, and sexual satisfaction, in adult males with congenital adrenal hyperplasia. Endocrine 2014. doi:10.1007/s12020-013-0161-2.

67. Pasterski V, Mastroyannopoulou K, Wright D, Zucker K, Hughes IA: Predictors of posttraumatic stress in parents of children diagnosed with a disorder of sex development. Arch Sex Behav 2013, 2014(43):369-375.

68. Crissman HP, Warner L, Gardner M, Carr M, Schast A, Quittner AL, Kogan $B$, Sandberg DE: Children with disorders of sex development: a qualitative study of early parental experience. Int J Pediatr Endocrinol 2011, 2011:10.

69. Liao LM, Tacconelli E, Wood D, Conway G, Creighton SM: Adolescent girls with disorders of sex development: a needs analysis of transitional care. J Ped Urol 2010, 6:609-613.

70. Loughlin E: The Family. In Disorders of Sex Development: An Integrated Approach, Volume Chapter 19. Edited by Hutson JM, Warne GL, Grover SR. Berlin: Springer; 2012:193-200.

71. Magritte $\mathrm{E}$ : Working together in placing the long term interests of the child at the heart of the DSD evaluation. J Ped Urol 2012, 2012(8):571-575.

72. Roen K, Pasterski V: Psychological research and intersex/DSD: recent developments and future directions. Psychol Sex Psychol Sex 2013. doi:10.1080/19419899.2013.831218.

73. Meyer-Bahlburg HFL: Psychoendocrinology of Congenital Adrenal Hyperplasia. In Genetic Steroid Disorders, MI New, Volume Chapter 10. New York: Elsevier; 2014:285-300.

74. Tannour-Louet M, Han S, Corbett ST, Louet JF, Yatsenko S, Meyers L, Shaw CA, Kang SH, Cheung SW, Lamb DJ: Identification of de novo copy number variants associated with human disorders of sexual development. PLOS One 2010, 5:e15392.

75. White S, Ohnesorg T, Notini A, Roeszler K, Hewitt J, Daggag H, Smith C, Turbitt E, Gustin S, van den Bergen J, Miles D, Western P, Arboleda V, Schumacher V, Gordon L, Bell K, Bengtsson H, Speed T, Hutson J, Warne G, Harley V, Koopman P, Vilain E, Sinclair A: Copy number variation in patients with disorders of sex development due to $46, X Y$ gonadal dysgenesis. PLoS One 2011, 6:e17793. 
76. Baxter RM, Vilain E: Translational genetics for diagnosis of human disorders of sex development. Annu Rev Genomics Hum Genet 2013, 14:371-392

77. Mazur T, Colsman M, Sandberg D: Intersex: Definition, Examples, Gender Stability, and the Case Against Merging With Transsexualism. In Principles of Transgender Medicine and Surgery. Edited by Etter R, Monstrey S, Elyer AS. New York: The Haworth Press, Inc.; 2007:235-259.

78. de Vries AL, Steensma TD, Doreleijers TA, Cohen-Kettenis PT: Puberty suppression in adolescents with gender identity disorder: a prospective follow-up study. J Sex Med 2011, 8:2276-2283.

79. Disorders of sex development translational research network. https:// dsdtrn.genetics.ucla.edu/. Published no date. Accessed May 17, 2014.

80. Ahmed SF, Rodie M, Jiang J, Sinnott RO: The european disorder of sex development registry: a virtual research environment. Sexual Develop 2010, 4:192-198.

81. Boyle MP, Sabadosa KA, Quinton HB, Marshall BC, Schechter MS: Key findings of the US Cystic Fibrosis Foundation's clinical practice benchmarking project. BMJ Qual Safety 2014, 23(Suppl 1):i15-i22.

82. Sandberg DE: Decision support for parents receiving genetic information about child's rare disease. http:/www.pcori.org/research-results/2012/ decision-support-parents-receivinggenetic-information-about-childs-rare. Published 2012. Accessed May 17, 2014.

83. Akhavan A, Merguerian PA, Grady RW, DiSandro M, Shnorhavorian M: Digital photographic measurement in hypospadias: validation and comparison to intraoperative measurement. J Pediat Urol 2014, 10:312-316.

84. Arboleda VA, Lee H, Parnaik R, Fleming A, Banerjee A, Ferraz-de-Souza B, Délot EC, Rodriquez-Fernandez IA, Braslavsky D, Bergadá I, Dell'Angelica EC, Nelson SF, Martinez-Agosto JA, Achermann JC, Vilain E: Mutations in the pcna-binding domain of cdkn1c cause image syndrome. Nat Genet 2012, 44:788-792.

85. Accord alliance. http://www.accordalliance.org/. Published no date. Accessed May 17, 2014.

doi:10.1186/1687-9856-2014-19

Cite this article as: Lee et al:: Advances in diagnosis and care of persons with DSD over the last decade. International Journal of Pediatric Endocrinology 2014 2014:19.

\section{Submit your next manuscript to BioMed Central and take full advantage of:}

- Convenient online submission

- Thorough peer review

- No space constraints or color figure charges

- Immediate publication on acceptance

- Inclusion in PubMed, CAS, Scopus and Google Scholar

- Research which is freely available for redistribution 